\title{
Cyclic Strain Enhances Cellular Uptake of Nanoparticles
}

\author{
Jia Hu and Yaling Liu \\ Department of Mechanical Engineering and Mechanics, Bioengineering Program, Lehigh University, Bethlehem, PA 18015, USA
}

Correspondence should be addressed to Yaling Liu; yal310@lehigh.edu

Received 26 February 2015; Revised 21 June 2015; Accepted 7 July 2015

Academic Editor: Rossella Bedini

Copyright (C) $2015 \mathrm{~J}$. Hu and Y. Liu. This is an open access article distributed under the Creative Commons Attribution License, which permits unrestricted use, distribution, and reproduction in any medium, provided the original work is properly cited.

\begin{abstract}
Nanoparticles (NPs) have gained increasing interest in recent years due to their potential use as drug carrier, imaging, and diagnostic agents in pharmaceutical and biomedical applications. While many cells in vivo experience mechanical forces, little is known about the correlation of the mechanical stimulation and the internalization of NPs into cells. This paper investigates the effects of applied cyclic strain on NP uptake by cells. Bovine aortic endothelial cells (BAECs) were cultured on collagen-coated culture plates and placed under cyclic equal-axial strains. NPs of sizes ranging from 50 to $200 \mathrm{~nm}$ were loaded at a concentration of $0.02 \mathrm{mg} / \mathrm{mL}$ and cyclic strains from 5 to $15 \%$ were applied to the cells for one hour. The cyclic strain results in a significant enhancement in NP uptake, which increases almost linearly with strain level. The enhanced uptake also depends on size of the NPs with the highest uptake observed on $100 \mathrm{~nm}$ NP. The effect of enhanced NP uptake lasts around 13 hours after cyclic stretch. Such in vitro cell stretch systems mimic physiological conditions of the endothelial cells in vivo and could potentially serve as a biomimetic platform for drug therapeutic evaluation.
\end{abstract}

\section{Introduction}

In the past decades, rapid progress has been made in nanoparticle (NP) technologies for the development of disease diagnosis and therapy [1]. Significant efforts have been made in the design of surface functionalized and bioconjugated NPs [2]. It was found that cellular uptake of NP efficiency and quantity depends on various nanoparticle characteristics, including the NP concentration [3], size [4], shape [5], and surface chemical structures [6]. However, these discoveries have not yet been applied to effective targeted therapies due to the complexity of the in vivo environment that severely inhibits their efficiency. This must be overcome to fully exploit the potential of NPs to improve drug pharmacokinetics and pharmacodynamics.

Endothelial cells (ECs) form the interior of the blood vessels and serve as a major barrier for therapeutic agents passing through the bloodstream to the target tissues [7]. Recent studies have focused on targeting the endothelium with NPs as therapeutic agents for a variety of targeted therapeutics because of the large population of ECs in the tissue and blood flow [8]. Nanoparticles (NPs) can serve as containers for the targeting of therapeutics to specific location and increasing the resistance time in the body [9]. NP entrance into cells depends on not only the size of the NP, but also the surface coating and charge [10]. For example, the efficiency of carboxydextran-coated superparamagnetic iron oxide nanoparticles (SPION) uptake was correlated to the amount of carboxyl groups on the NP surface [11]. Cationic D, L-polylactide- (PLA-) NP entered Hela cells in greater amounts than anionic PLA-NP [12]. In this study, we investigate the endothelial cell uptake of carboxylated polystyrene NPs (PS-COOH) with positive charge.

ECs in vivo are constantly exposed to a variety of forces that generate mechanical stresses within the cell body including shear stress, hydrostatic pressure, and cyclic stretch caused by the pulsatile blood flow [13]. The study of endothelial response to biomechanical forces through in vitro experiments assists in the understanding of endothelial function, mechanisms involved in endothelial damage, and therapeutic targeting. Researchers reported that cyclic stretch affects the mechanical properties of ECs, such as cell proliferation [14], cytoskeletal structure [15], signal transduction [16], and gene expression and transfer [17]. However very few researches have been done to quantify the effect of cyclic stretching on the cellular uptake of NPs [18]. The aim of 
this study is to investigate the effects of cyclic stretch on the cellular uptake of NPs and its dependence on NP size through controlled tests. The enhancement of NPs uptake by ECs under physiologically relevant mechanical stimulation might be useful for the development of targeted therapeutics.

In this study, we cultured the bovine aortic endothelial cells (BAECs) on six-well plates and stretched the membrane with a cyclic stretcher to investigate the endothelial cell uptake of NPs. The goal of this study was to find out the correlation between cyclic strain and the uptake of NPs into endothelial cells. The results showed that cyclic stretch notably enhanced the cellular uptake of NPs. We further explored the stretch effect on the cellular uptake of NPs by changing the cyclic strain strength and particle size. The results indicated that the enhanced cellular uptake was sizedependent with an optimal particle size of $100 \mathrm{~nm}$. In addition, the cellular uptake is strain-dependent and improves as the strain level increases.

\section{Materials and Methods}

All reagents and equipment, unless otherwise indicated, were purchased from Sigma-Aldrich USA.

2.1. Cell Culture. The bovine aortic endothelial cells (BAECs) which were provided by Cell Applications (San Diego, CA) were cultured in $25 \mathrm{~cm}^{2}$ cell culture flasks using a medium containing Dulbecco's modified Eagle's medium (DMEM), 10\% heat-inactivated fetal bovine serum, and $1 \%$ Penicillin/Streptomycin inside a humidified incubator at 5\% $\mathrm{CO}_{2}$ and $37^{\circ} \mathrm{C}[19,20]$. The cells were passaged in a split ratio of $1: 2$. All experiments were performed with cells between passages 10 and 15.

2.2. Seeding of BAECs for Cyclic Stretch Study. Cell culture medium was aspirated from the flask and the cell monolayer was washed with sterile phosphate buffered saline (PBS, $\mathrm{pH}$ 7.4). After removing the PBS, $3 \mathrm{~mL}$ trypsin was added to the flask. The flask was placed in the incubator (Thermo Scientific, USA) at $37^{\circ} \mathrm{C}$ for $3 \mathrm{~min}$ to allow for cell detachment. Fresh cell culture medium was added to the flask and flushed with a $10 \mathrm{~mL}$ pipette several times to ensure that all the cells were in suspension. Afterwards the cell suspension was transferred to a $15 \mathrm{~mL}$ tube. The cells were centrifuged at $1500 \mathrm{rpm}$ for $5 \mathrm{~min}$ in order to pellet the cells. The supernatant was discarded and cells were resuspended in fresh cell culture medium. For the cyclic stretch study, BAECs were seeded into six-well, collagen type I coated Bioflex plates (Flexcell International Corp., NC, USA) at $6 \times 10^{5}$ cells/well, determined by a hemocytometer count.

2.3. NP Uptake Assay and Cyclic Stretch. Carboxylate-modified fluorescent polystyrene NPs $(50 \mathrm{~nm}, 100 \mathrm{~nm}, 200 \mathrm{~nm})$ were sonicated for $15 \mathrm{~min}$ to break apart possible aggregations and diluted to the final concentration of $0.02 \mathrm{mg} / \mathrm{mL}$ in fresh culture medium [21]. This concentration is nontoxic and can be applied without overloading the cells with nanoparticles. After cells reached $80 \%$ confluence in the six-well plates, the media were discarded and replaced with NP medium, and BAECs from the test group were subjected to cyclic stretch with frequency of $1 \mathrm{~Hz}$ and cyclic strain $(5 \%, 10 \%$, and $15 \%$ ) for $1 \mathrm{~h}$. A Flexcell tension system (Flexcell International Corp., NC, USA) was used to apply physiological equibiaxial cyclic strain for a wide range of durations, amplitudes, and frequencies $[22,23]$. The control group was not subjected to the cyclic stretch while kept in the same condition as the test group.

2.4. Analysis of Cellular Uptake. After loading the NP for $1 \mathrm{~h}$, the cells were rinsed with DPBS to eliminate free particles that were not taken up by the cells. Phase contrast and fluorescence images were acquired with a Nikon phase contrast microscope using a 20x lens (Olympus, JP). For quantitative analysis of cellular uptake, $0.5 \%$ Triton X-100 in a $0.2 \mathrm{M} \mathrm{NaOH}$ solution was added to destroy the cell membrane [4]. The cell medium was transferred to a 96-well plate. Quantitative measurement was then performed by the definite quantitative determination of each cell lysate with a fluorescence Infinite M200 Pro microplate reader (Tecan, Männedorf, Switzerland).

2.5. NP Localization and Cell Viability Assay. After cyclic stretch for $1 \mathrm{~h}$, cells were washed three times with PBS, fixed in $4 \%$ paraformaldehyde for 30 mins, and then washed three times with PBS. Afterwards, cells were permeabilized in $0.3 \%$ Triton X-100 for 5 mins at room temperature. Cells were washed three times with PBS and then incubated with DAPI to visualize nuclei. Cells viability was determined by staining the cells with Calcein AM.

2.6. Statistical Analysis. The cellular uptake of nanoparticles (\%) was calculated as the fluorescence of the NPs taken up by the cells relative to the total fluorescence of the NPs in the solution. Results are expressed as means \pm standard error of the mean (SEM). Statistical analysis was conducted by using Student's $t$-test, with $P<0.05$ as the significant difference. Each data point was performed with a minimum of three independent experiments $(n=3)$.

\section{Results}

3.1. Size-Dependent Uptake of NPs. In this study, nanoparticles of different sizes $50 \mathrm{~nm}, 100 \mathrm{~nm}$, and $200 \mathrm{~nm}$ were used to evaluate the correlation between particle sizes and the internalization of NPs into endothelial cells. The fluorescent dye embedded inside the NPs allows us to quantify cellular uptake through fluorescence images. Assuming that the fluorescence intensity is proportional to the number of fluorescent NPs, the average fluorescence yielded within individual cells indicates the cellular uptake of NPs. It should be mentioned that, in extracting the fluorescence intensity, the seeded cells were extensively washed using DPBS to remove any NPs adhered to the cell surface. Therefore, the fluorescence intensity accounts only for the internalized NPs. The cells were cultured in six-well plates for $24 \mathrm{~h}$ before loading the NPs for $1 \mathrm{~h}$. We further quantify the cellular uptake of NPs with a fluorescence Infinite M200 Pro microplate reader (Tecan, Männedorf, Switzerland, $\lambda_{\text {ex }} 488 \mathrm{~nm}, \lambda_{\mathrm{em}} 644 \mathrm{~nm}$ ). 


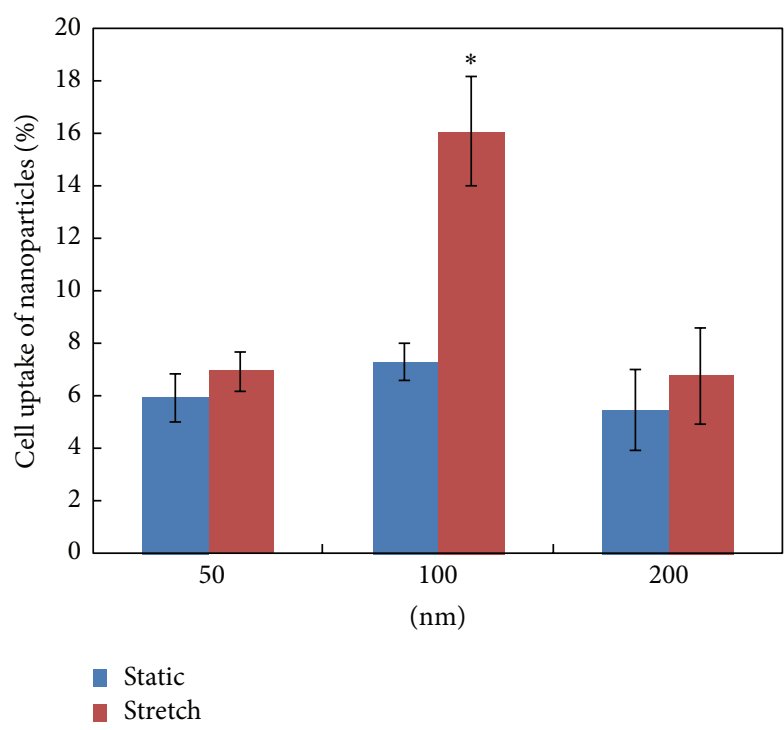

(a)

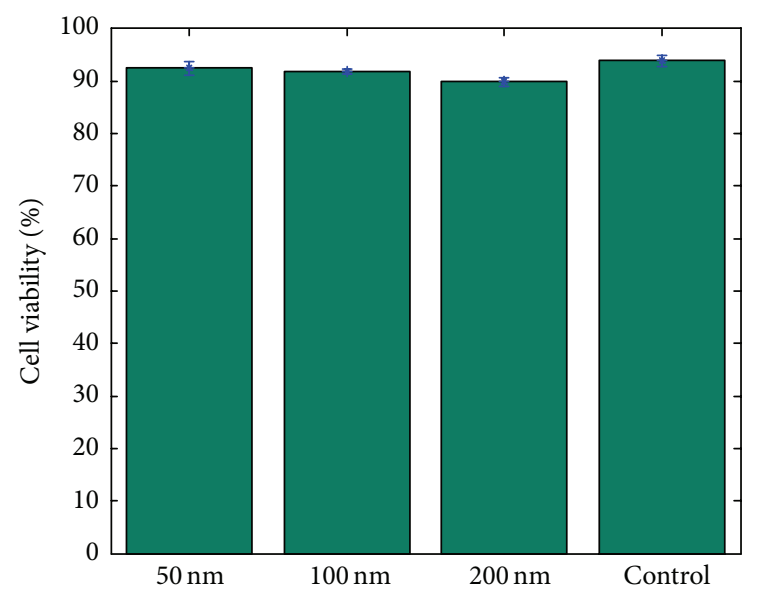

(b)

FIGURE 1: BAECs incubated with NPs under static and 15\% strain condition for $1 \mathrm{~h}$. (a) Cellular uptake efficiency of $50 \mathrm{~nm}, 100 \mathrm{~nm}$, and $200 \mathrm{~nm}$ particles. The uptake of $100 \mathrm{~nm}$ nanoparticles has significant enhancement after stretching compared to static condition. (b) Cell viability after incubation with NPs of different sizes and without NPs (control). Bars represent mean \pm SEM $(n=3)$. denotes significant differences $(p<0.05)$.

As shown in Figure 1(a), BAECs uptake more $100 \mathrm{~nm}$ NPs than $50 \mathrm{~nm}$ and $200 \mathrm{~nm}$ NPs. The result indicates that cellular uptake exhibited size-dependence for the NPs in BAECs, and the optimal size was around $100 \mathrm{~nm}$. This result is consistent with other investigations that cells uptake more $100 \mathrm{~nm}$ than other sizes $[4,24]$.

\subsection{Comparison on the Stretch-Enhanced Uptake of the Dif-} ferent Sized NPs. We compared the cyclic stretch effect on $50 \mathrm{~nm}, 100 \mathrm{~nm}$, and $200 \mathrm{~nm}$ particles uptake separately. We found that, after stretching with $15 \%$ strain for $1 \mathrm{~h}$, the uptake enhancement of $100 \mathrm{~nm}$ particles was much higher than those of $50 \mathrm{~nm}$ and $200 \mathrm{~nm}$ particles (Figure 1(a)). While $50 \mathrm{~nm}$ and $200 \mathrm{~nm}$ particles show around 20\% higher cellular uptake after stretching for $1 \mathrm{~h}, 100 \mathrm{~nm}$ particles show more than twofold enhancement.

We also investigated the viability of cells with Calcein AM staining after incubation with $50 \mathrm{~nm}, 100 \mathrm{~nm}$, and $200 \mathrm{~nm}$ NPs. Comparing with cells without NP exposure, no significant differences were found as shown in Figure 1(b). This indicates that incubation with NPs from 50 to $200 \mathrm{~nm}$ does not have apparent effect on cell viability.

\subsection{Stretch Effect on Cellular Uptake of NPs. Since it was} found that $100 \mathrm{~nm}$ NPs have the highest uptake in cells compared to $50 \mathrm{~nm}$ and $200 \mathrm{~nm}$ NPs, we used carboxylate polystyrene NPs (PS-COOH) with diameters of $100 \mathrm{~nm}$ to study the dependence of strain level on cellular uptake. BAECs were cultured on six-well plates for $24 \mathrm{~h}$ before loading NPs into the culture media. Fluorescence and phase contrast images were taken after loading NPs for $1 \mathrm{~h}$ at different strain levels (Figure 2). The images show that the stretch influences the cellular NP uptake quantity. A microplate reader was used to quantify the uptake of NPs in each plate. For each sample, the negative control of cells without NPs was also determined. We found that the application of cyclic stretch significantly promotes the cellular uptake of $100 \mathrm{~nm}$ polystyrene nanoparticles relative to static cells, as depicted in Figure 3. This qualitative observation agrees with that reported by Huh et al. [25]. We further compared the cellular uptake of NPs with different cyclic strains: 5\%,10\%, and $15 \%$. Results in Figure 3(a) indicate that the cellular uptake of NPs is strain-dependent, and higher strain leads to more NP uptake. The endothelial cells in vivo are exposed to shear stress and cyclic stretch induced by the pulsatile blood flow. The levels of applied uniform strain (5 to 15\%) cover the range of strain experienced by endothelial cells in vivo. This result indicates that mechanical strain influences NP uptake, which is not considered in the static culture dish work. NP uptake observed in such a cyclic strain system is closer to one that might be observed in animal studies for drug targeting and toxicology applications.

To make sure cyclic stretch does not get cells detached, we also examined the detachment of cells after incubation with $100 \mathrm{~nm}$ NPs under cyclic strain (5\%,10\%, and 15\%) for $1 \mathrm{~h}$. No significant difference of cell detachment was found compared to static cells as shown in Figure 3(b), partially because the plates were coated with collagen type I which can help cell adhesion on the surface. The result indicates that the strain level from 5 to $15 \%$ will not apparently lead to the detachment of cells.

3.4. NPs Localization within the Cells. To figure out the distribution of NPs within the cell, position of the nuclei in 

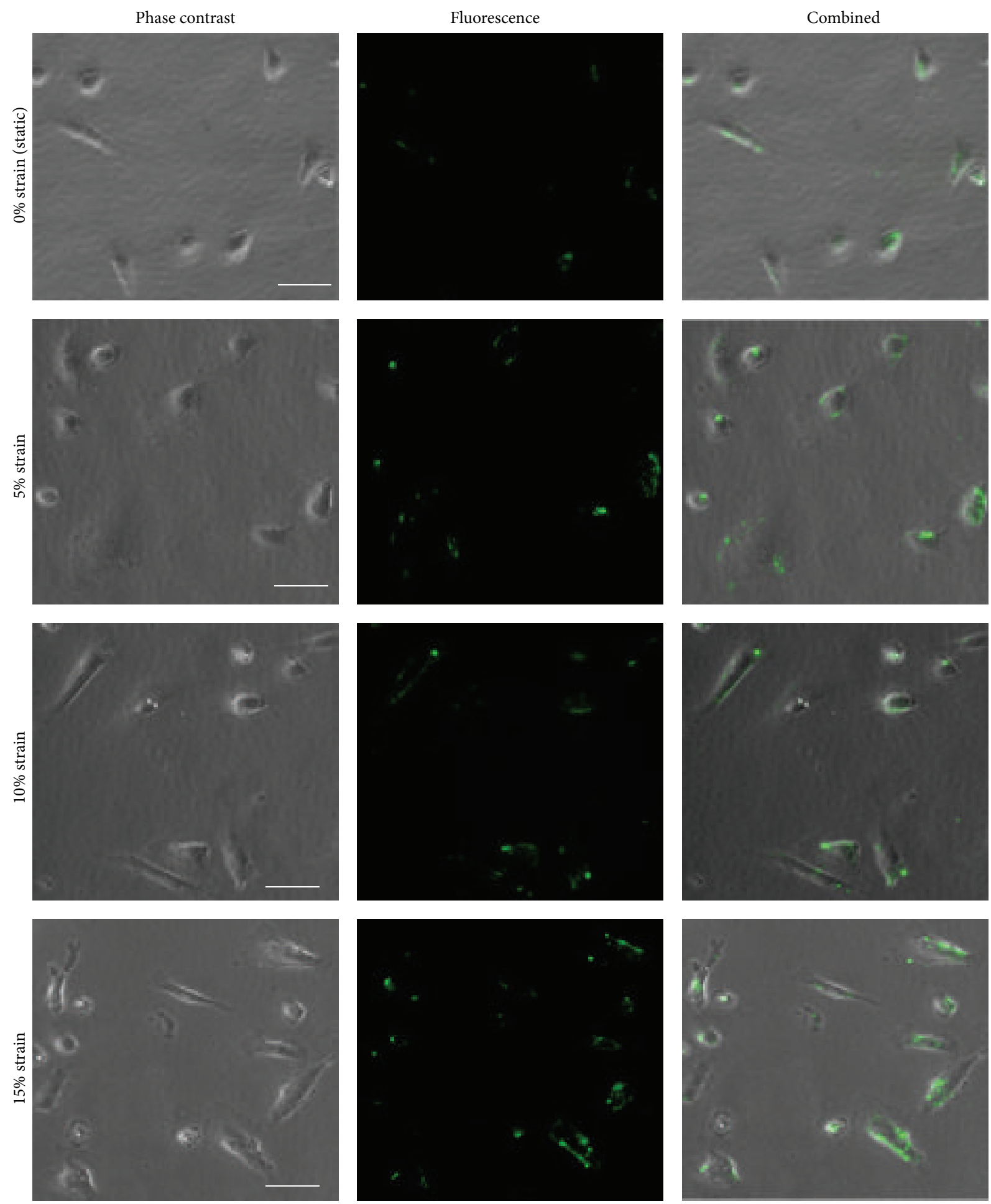

Figure 2: Cellular uptake of fluorescent NPs by the cells on plates with different strain ratio (0\%,5\%, 10\%, and $15 \%)$ (scale bar: $20 \mu \mathrm{m})$. Cells were cultured on substrates for $24 \mathrm{~h}$ before loading the NPs. Images were taken after loading the NPs for $1 \mathrm{~h}$.

each cell was labeled with DAPI staining. The intracellular localization of the NPs was recorded after $1 \mathrm{~h}$ using fluorescence microscopy. As shown in Figure 4, most of the NPs were located outside of the nucleus and within the cell cytosol.
This result is consistent with that reported in literature $[2,3]$. Additionally, cyclic stretch did not change the localization of NPs within the cells as shown in Figure 4(a). NPs are still localized in the cell cytosol after stretching. 


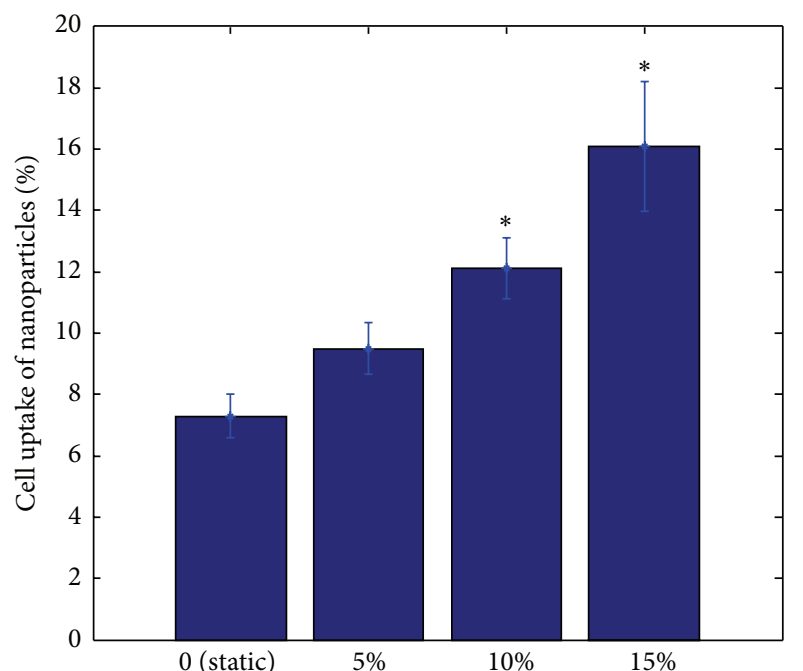

(a)

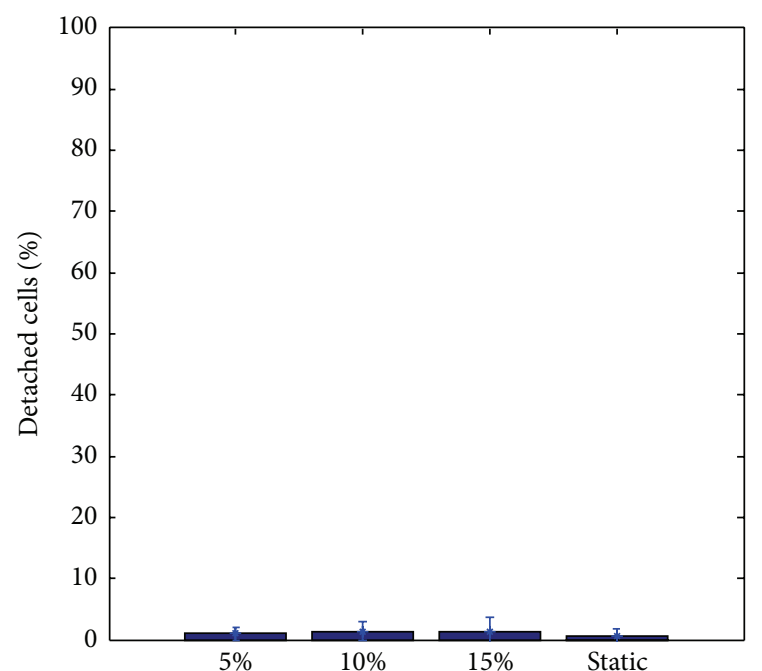

(b)

FIGURE 3: Cell incubation with nanoparticles after stretching for $1 \mathrm{~h}$ with cyclic strain $(5 \%, 10 \%, 15 \%)$ and at static condition (control group). (a) Cellular uptake efficiency of nanoparticles. (b) Percentage of detached cells indicates no significant detachment difference. Bars represent mean $\pm \operatorname{SEM}(n=3) .^{*} p<0.05$ versus static cells.

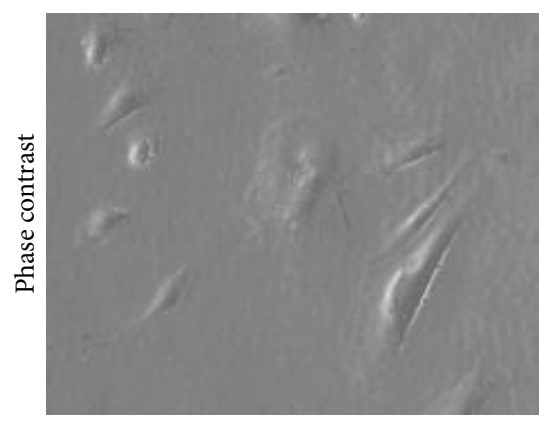

(a)

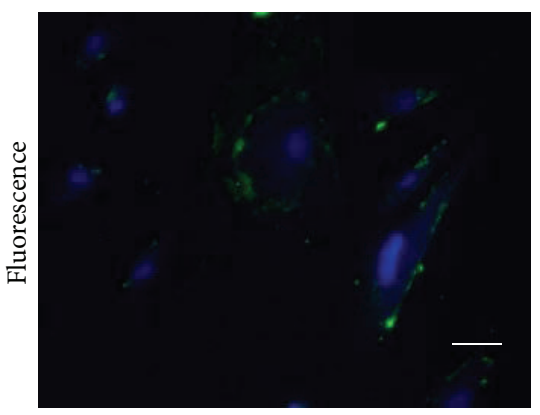

(b)

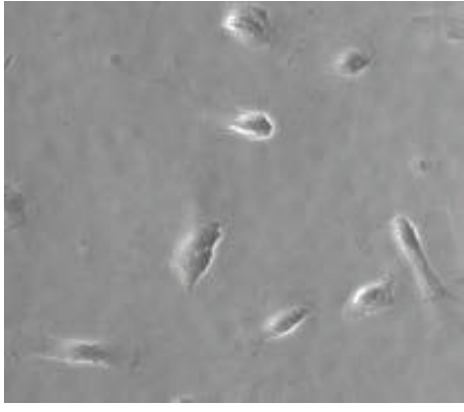

(c)

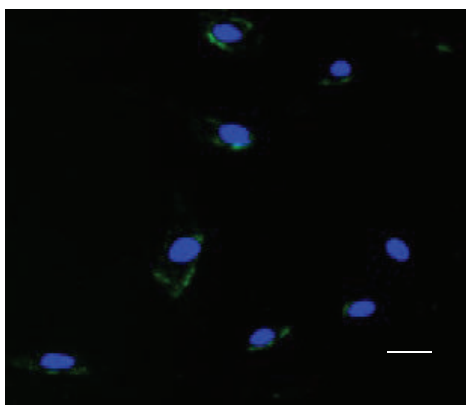

(d)

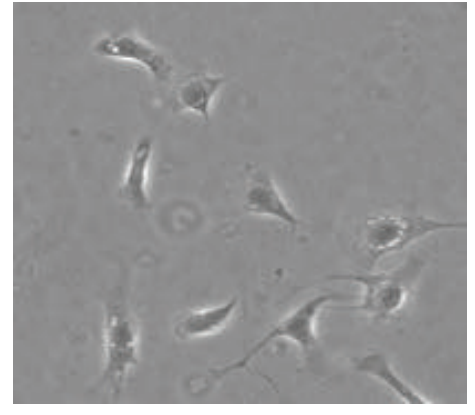

(e)

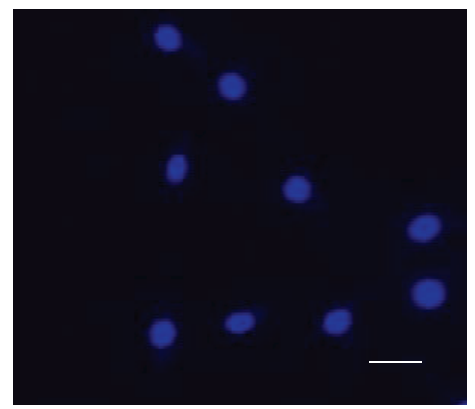

(f)

FIGURE 4: Phase contrast and fluorescence images of BAECs after nanoparticles uptake for $1 \mathrm{~h}$ (scale bar: $10 \mu \mathrm{m})$. The nucleus in each cell was labeled with DAPI staining (blue color). (a-b) Representing uptake of $100 \mathrm{~nm}$ nanoparticles by BAECs with $15 \%$ stretching for $1 \mathrm{~h}$. (cd) Representing uptake of $100 \mathrm{~nm}$ NPs by BAECs incubated for $1 \mathrm{~h}$ without stretching. Nanoparticles (green color) are seen outside of the nucleus. (e-f) Control experiment without nanoparticle incubation. 


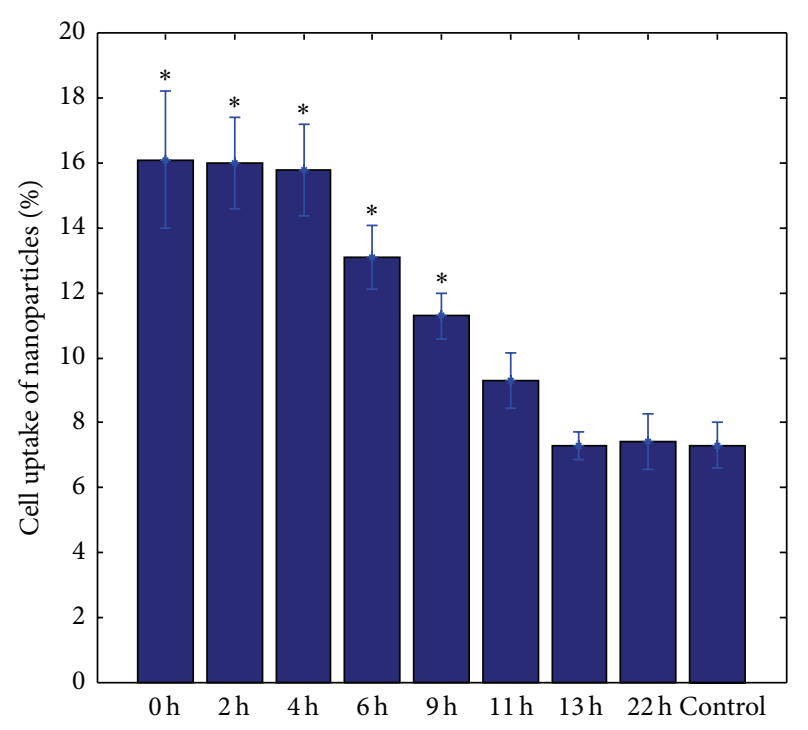

FIgURE 5: The cellular nanoparticle uptake after stretching $1 \mathrm{~h}$ and waiting for $0 \mathrm{~h}, 2 \mathrm{~h}, 4 \mathrm{~h}, 6 \mathrm{~h}, 9 \mathrm{~h}, 11 \mathrm{~h}, 13 \mathrm{~h}$, and $22 \mathrm{~h}$. Control group shows the cells without stretching. The uptake of nanoparticles decreased after $4 \mathrm{~h}$ and recovered to static condition after $13 \mathrm{~h}$. Bars represent mean $\pm \operatorname{SEM}(n=3) .{ }^{*} p<0.05$ versus control group.

3.5. Time Duration of NP Uptake Enhancement Effect. We further explore how long this stretch-enhanced NPs uptake effect lasts. To investigate the effect duration time, we first stretched the cells for $1 \mathrm{~h}$ without loading the NPs. We then loaded the NPs into each plate after waiting for $0,2,4$, $6,9,11,13$, and $22 \mathrm{~h}$ separately. Fluorescence signals were quantified by a microplate reader for each sample. The cells exposed to cyclic stretching uptake more NPs than the control group of cells. The NP uptake enhancement effect after stretching decreases nonlinearly with time and disappears after $13 \mathrm{~h}$ compared to the cells without stretching, as shown in Figure 5. The cellular uptake of NPs did not obviously change even $4 \mathrm{~h}$ after stretching and began to decrease $6 \mathrm{~h}$ after stretching. This result indicates that the effect of cyclic stretch on cellular NP uptake can last for as long as $13 \mathrm{~h}$.

\section{Discussion}

Nanoparticles as drug delivery carriers or imaging tools may play a pivotal role in improving biomedical therapies [26]. In vitro experiments were usually executed to investigate the transport, binding, and uptake behaviors of nanoparticles. The development of in vitro models that mimic the in vivo environment is highly desirable. For example, Huh et al. develop a biomimetic microsystem that reconstitutes the critical functional alveolar capillary interface of the human lung to investigate cell reactions such as toxicity or the formation of reactive oxygen species [25]. Compared to static culture dish, the addition of cyclic stretching provides physiological conditions closer to that in vivo.

The main outcome of our study was that, under cyclic stretch conditions, more carboxylate polystyrene NPs were internalized by BAECs compared to static cell culture conditions and such enhancement is NP size and strain level dependent. To our understanding, few investigations were previously reported about the correlation between cyclic stretch and internalization of NPs into endothelial cells. Rouse et al. examined the cell viability, quantum dots (QD) uptake, and cytokine production under $10 \%$ cyclic strain condition [27]. Their results indicate that the addition of stain results in an increase in QD uptake by human epidermal keratinocytes (HEK). They mentioned that application of physiological load conditions can increase cell membrane permeability, thereby increasing the concentration of $\mathrm{QD}$ nanoparticles in cells. Other research further demonstrated that cyclic stretch leads to the generation of reactive oxygen species, which increase monolayer permeability via activation of $\mathrm{NF}-\kappa \mathrm{B}$ and extracellular signal-regulated kinase (ERK) [28].

Based on the experimental results in this study, the enhanced NP uptake behavior will disappear after $13 \mathrm{~h}$. This may be related to the response of cell to mechanical strains. Other studies also reported that repeated stretches resulted in the trafficking and remodeling of caveolin-3-rich membrane domains and accelerated turnover of membrane glycosphingolipids [29]. The mechanical strain effects on the cytoskeleton also play an important role in mechanotransduction [30, 31]. The changes in the arrangement of the cytoskeleton and the stretch-induced unfolding of caveolae might reflect the mechanisms of the cellular adaptation to mechanical strains which may affect endocytosis events [32]. This may lead to a changed uptake rate of NPs in BAECs in a strain-dependent manner. When the mechanical strains disappear, the cellular uptake of NPs recovers to normal condition after $13 \mathrm{~h}$.

The results of this in vitro study demonstrate that mechanical strain influences the BAEC's ability to internalize NPs. This study has also shown that differences occur with different cyclic strains and particles sizes. More testing in the future, such as using a different endothelial cell type, strain frequency, stretch time, particle type, chemical structure, and NP concentration, can be performed to better understand how mechanical strain affects the uptake of NPs into endothelial cells.

\section{Conclusions}

Mechanical strain is shown to enhance cellular uptake of nanoparticles. The cell internalization of nanoparticles is size-dependent and has an optimal size of about $100 \mathrm{~nm}$. Additionally, the cell internalization of nanoparticles is strain-dependent and shows more internalization with higher strain levels. This enhanced nanoparticle uptake behavior can last for $13 \mathrm{~h}$ and disappears afterwards. Future research is needed to investigate the intercellular processes and activities affected by cyclic stretch to further understand the uptake mechanism. The strain level used in this study is similar to that in physiological systems; thus it may be helpful to understand targeted nanoparticle drug delivery in vivo.

\section{Conflict of Interests}

The authors declare that there is no conflict of interests regarding the publication of this paper. 


\section{Acknowledgments}

The authors acknowledge the supports of this work from National Science Foundation (NSF) CAREER Grant CBET1113040, NSF CBET-1264808, and National Institute of Health (NIH) Grant EB015105.

\section{References}

[1] S. Andreescu, "Nanoparticle-based technologies for diagnosis and therapy," Abstracts of Papers of the American Chemical Society, 244, 2012.

[2] M. G. Qaddoumi, H. Ueda, J. Yang, J. Davda, V. Labhasetwar, and V. H. L. Lee, "The characteristics and mechanisms of uptake of PLGA nanoparticles in rabbit conjunctival epithelial cell layers," Pharmaceutical Research, vol. 21, no. 4, pp. 641-648, 2004.

[3] L. Jiang, X. Li, L. Liu, and Q. Zhang, "Cellular uptake mechanism and intracellular fate of hydrophobically modified pullulan nanoparticles," International Journal of Nanomedicine, vol. 8, no. 1, pp. 1825-1834, 2013.

[4] A. R. Xu, M. Yao, G. Xu et al., "A physical model for the size-dependent cellular uptake of nanoparticles modified with cationic surfactants," International Journal of Nanomedicine, vol. 7, pp. 3547-3554, 2012.

[5] X. L. Huang, X. Teng, D. Chen, F. Tang, and J. He, “The effect of the shape of mesoporous silica nanoparticles on cellular uptake and cell function," Biomaterials, vol. 31, no. 3, pp. 438-448, 2010.

[6] H. Y. Nam, S. M. Kwon, H. Chung et al., "Cellular uptake mechanism and intracellular fate of hydrophobically modified glycol chitosan nanoparticles," Journal of Controlled Release, vol. 135, no. 3, pp. 259-267, 2009.

[7] B. R. Zetter, "The endothelial-cells of large and small bloodvessels," Diabetes, vol. 30, no. 2, pp. 24-28, 1981.

[8] S. P. Samuel, N. Jain, F. O’Dowd et al., "Multifactorial determinants that govern nanoparticle uptake by human endothelial cells under flow," International Journal of Nanomedicine, vol. 7, pp. 2943-2956, 2012.

[9] W. H. De Jong and P. J. A. Borm, "Drug delivery and nanoparticles: applications and hazards," International Journal of Nanomedicine, vol. 3, no. 2, pp. 133-149, 2008.

[10] L. W. Zhang and N. A. Monteiro-Riviere, "Mechanisms of quantum dot nanoparticle cellular uptake," Toxicological Sciences, vol. 110, no. 1, pp. 138-155, 2009.

[11] V. Mailänder, M. R. Lorenz, V. Holzapfel et al., "Carboxylated superparamagnetic iron oxide particles label cells intracellularly without transfection agents," Molecular Imaging and Biology, vol. 10, no. 3, pp. 138-146, 2008.

[12] J. Dausend, A. Musyanovych, M. Dass et al., "Uptake mechanism of oppositely charged fluorescent nanoparticles in Hela cells," Macromolecular Bioscience, vol. 8, no. 12, pp. 1135-1143, 2008.

[13] N. Azuma, S. A. Duzgun, M. Ikeda et al., "Endothelial cell response to different mechanical forces," Journal of Vascular Surgery, vol. 32, no. 4, pp. 789-794, 2000.

[14] G. B. Chapman, W. Durante, J. D. Hellums, and A. I. Schafer, "Physiological cyclic stretch causes cell cycle arrest in cultured vascular smooth muscle cells," American Journal of PhysiologyHeart and Circulatory Physiology, vol. 278, no. 3, pp. H748H754, 2000.

[15] M. Morioka, H. Parameswaran, K. Naruse et al., "Microtubule dynamics regulate cyclic stretch-induced cell alignment in human airway smooth muscle cells," PLoS ONE, vol. 6, no. 10, Article ID e26384, 2011.

[16] K. G. Birukov, "Cyclic stretch, reactive oxygen species, and vascular remodeling," Antioxidants \& Redox Signaling, vol. 11, no. 7, pp. 1651-1667, 2009.

[17] M. Eldib and D. A. Dean, "Cyclic stretch of alveolar epithelial cells alters cytoskeletal micromechanics," Biotechnology and Bioengineering, vol. 108, no. 2, pp. 446-453, 2011.

[18] A. Sharei, R. Poceviciute, E. L. Jackson et al., "Plasma membrane recovery kinetics of a microfluidic intracellular delivery platform," Integrative Biology, vol. 6, no. 4, pp. 470-475, 2014.

[19] J. Hu, C. Hardy, C.-M. Chen, S. Yang, A. S. Voloshin, and Y. Liu, "Enhanced cell adhesion and alignment on micro-wavy patterned surfaces," PLoS ONE, vol. 9, no. 8, Article ID e104502, 2014.

[20] J. Hatami, M. Tafazzoli-Shadpour, N. Haghighipour, M. A. Shokrgozar, and M. Janmaleki, "Influence of cyclic stretch on mechanical properties of endothelial cells," Experimental Mechanics, vol. 53, no. 8, pp. 1291-1298, 2013.

[21] C. Huang, P. J. Butler, S. Tong, H. S. Muddana, G. Bao, and S. Zhang, "Substrate stiffness regulates cellular uptake of nanoparticles," Nano Letters, vol. 13, no. 4, pp. 1611-1615, 2013.

[22] N. Von Offenberg Sweeney, P. M. Cummins, Y. A. Birney, J. P. Cullen, E. M. Redmond, and P. A. Cahill, "Cyclic strainmediated regulation of endothelial matrix metalloproteinase-2 expression and activity," Cardiovascular Research, vol. 63, no. 4, pp. 625-634, 2004.

[23] A. Colombo, P. A. Cahill, and C. Lally, "An analysis of the strain field in biaxial Flexcell membranes for different waveforms and frequencies," Proceedings of the Institution of Mechanical Engineers, Part H: Journal of Engineering in Medicine, vol. 222, no. H8, pp. 1235-1245, 2008.

[24] K. Y. Win and S.-S. Feng, "Effects of particle size and surface coating on cellular uptake of polymeric nanoparticles for oral delivery of anticancer drugs," Biomaterials, vol. 26, no. 15, pp. 2713-2722, 2005.

[25] D. Huh, B. D. Matthews, A. Mammoto, M. Montoya-Zavala, H. Y. Hsin, and D. E. Ingber, "Reconstituting organ-level lung functions on a chip," Science, vol. 328, no. 5986, pp. 1662-1668, 2010.

[26] D. A. Groneberg, M. Giersig, T. Welte, and U. Pison, "Nanoparticle-based diagnosis and therapy," Current Drug Targets, vol. 7, no. 6, pp. 643-648, 2006.

[27] J. G. Rouse, C. M. Haslauer, E. G. Loboa, and N. A. MonteiroRiviere, "Cyclic tensile strain increases interactions between human epidermal keratinocytes and quantum dot nanoparticles," Toxicology in Vitro, vol. 22, no. 2, pp. 491-497, 2008.

[28] N. Davidovich, B. C. DiPaolo, G. G. Lawrence, P. Chhour, N. Yehya, and S. S. Margulies, "Cyclic stretch-induced oxidative stress increases pulmonary alveolar epithelial permeability," The American Journal of Respiratory Cell and Molecular Biology, vol. 49, no. 1, pp. 156-164, 2013. 
[29] O. L. Gervásio, W. D. Phillips, L. Cole, and D. G. Allen, "Caveolae respond to cell stretch and contribute to stretchinduced signaling," Journal of Cell Science, vol. 124, no. 21, pp. 3581-3590, 2011.

[30] Y. Shao, X. Tan, R. Novitski et al., "Uniaxial cell stretching device for live-cell imaging of mechanosensitive cellular functions," Review of Scientific Instruments, vol. 84, no. 11, 2013.

[31] D. Kiyoshima, K. Kawakami, K. Hayakawa, H. Tatsumi, and M. Sokabe, "Force- and $\mathrm{Ca}^{2+}$-dependent internalization of integrins in cultured endothelial cells," Journal of Cell Science, vol. 124, no. 22, pp. 3859-3870, 2011.

[32] J. Dai and M. P. Sheetz, "Regulation of endocytosis, exocytosis, and shape by membrane tension," Cold Spring Harbor Symposia on Quantitative Biology, vol. 60, pp. 567-571, 1995. 

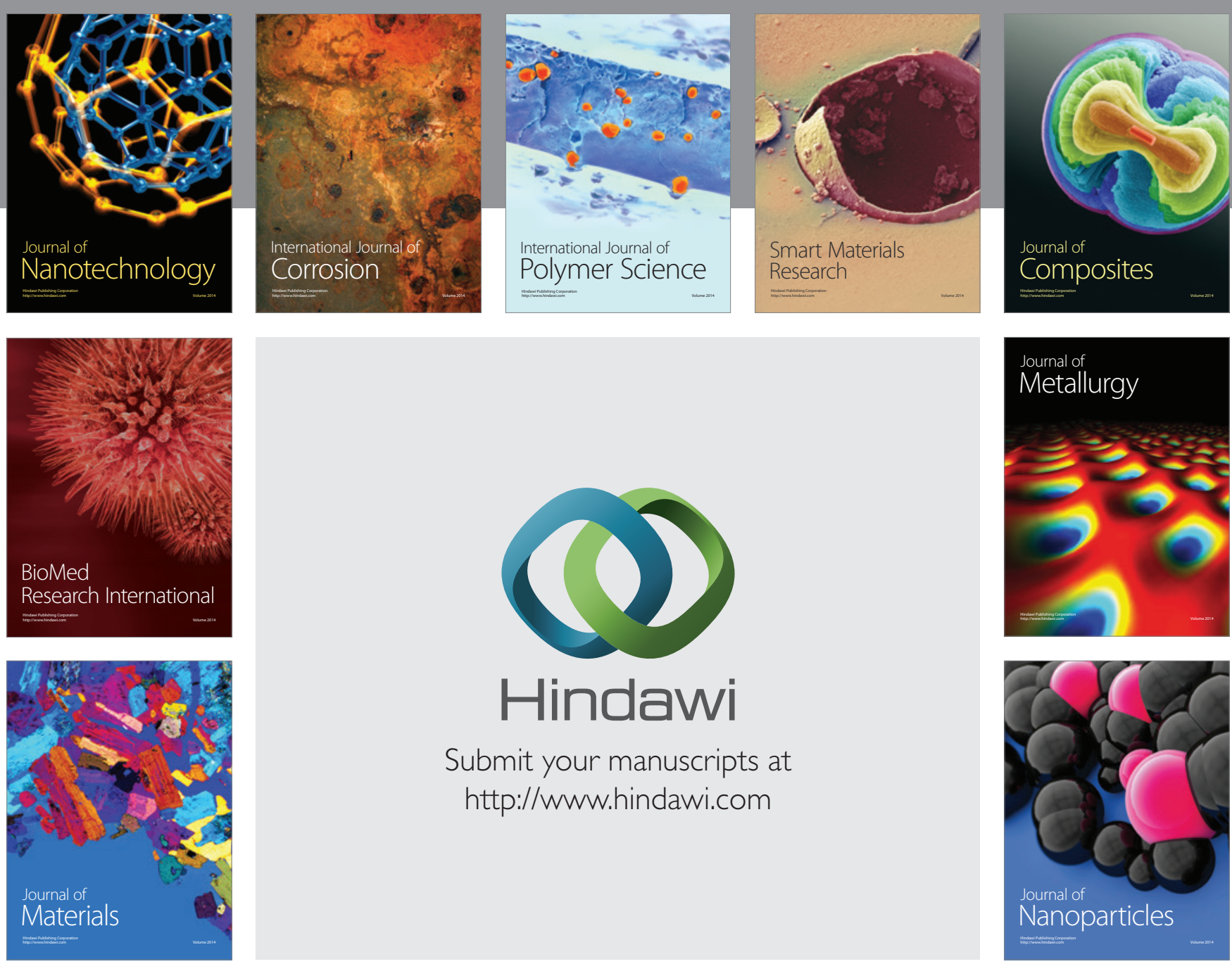

Submit your manuscripts at http://www.hindawi.com
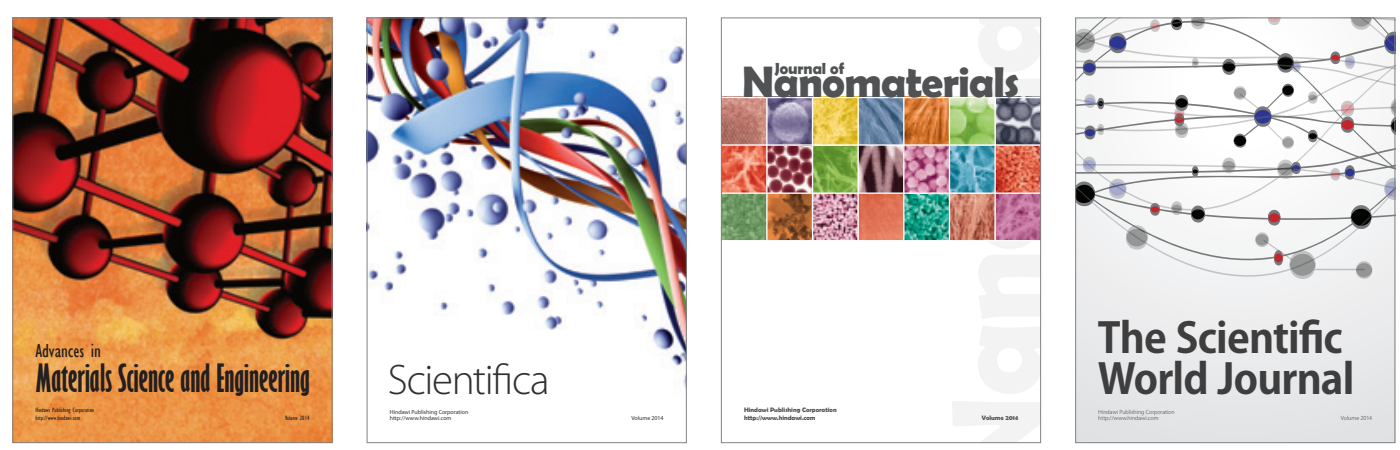

\section{The Scientific World Journal}
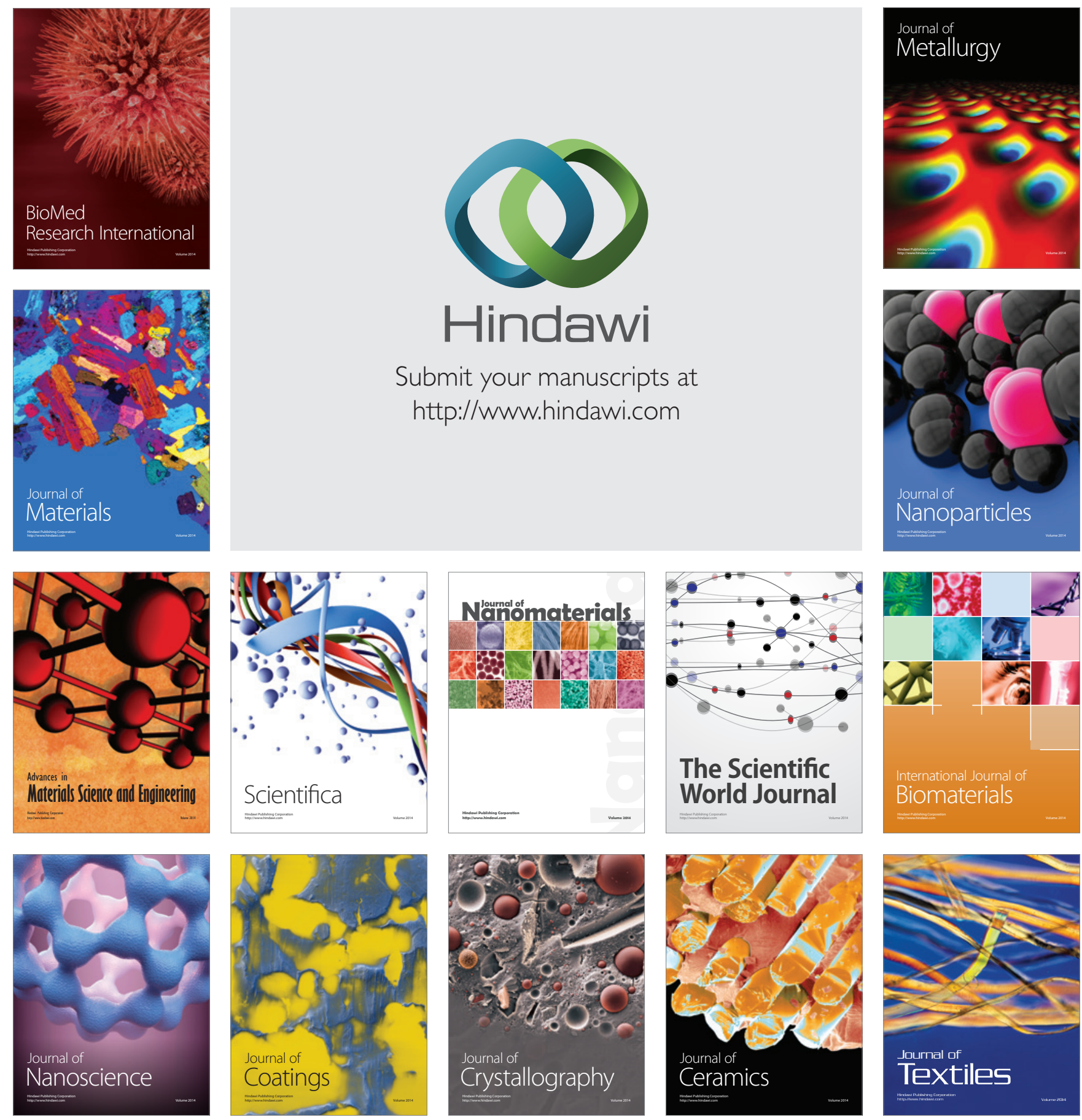